\title{
Ingeniería romana, obras públicas e importancia de las cosas públicas en derecho romano
}

\author{
Vanessa Ponte-Arrebola
}

\section{RESUMEN}

La habilidad y aptitud de los romanos en ingeniería civil, obras y trabajos públicos contribuyeron en gran parte al establecimiento y éxito de su civilización. Muchos de los bienes construidos estaban sometidos a la posibilidad de uso y disfrute del ciudadano: eran las denominadas res publicae in usu publico.

Palabras clave: Obras públicas romanas, Ingeniería civil, Utilidad pública, División de las cosas, Cosas públicas, Cosas fuera del comercio, res publicae in usu publico.

1 Doctora en Derecho y profesora de la Facultad de Derecho de la Universidad de Córdoba, Córdoba, España. Miembro del Consejo Científico Internacional de la revista búlgara especializada en derecho romano Ivs Romanvm y del Consejo Científico Internacional de la Revista búlgara especializada en derecho civil, Universidad de Sofía "Saint Kliment Ohridski", Sofía, Bulgaria. Premio a la innovación docente 2012 y a la labor docente 1999-2000. Creadora y directora de la revista interactiva on line Ivs Romanvm en Flipboard (https://flipboard. com/@ivsromanvm/ivs-romanvm-edcaaoaly), Córdoba, España. Autora de importantes publicaciones en el área de derecho administrativo romano. Correo-e: fd1 poarv@uco.es Fecha de recepción: 25 de julio de 2016. Fecha de modificación: 30 de agosto de 2016. Fecha de aceptación: 15 de septiembre de 2016. Para citar el artículo: Ponte-Arrebola, V. "Ingeniería romana, obras públicas e importancia de las cosas públicas en derecho romano", Revista digital de Derecho Administrativo, n. ${ }^{\circ} 17$, primer semestre, Universidad Externado de Colombia, 2017, pp. 111-139. DOI: http://dx.doi.org/10.18601/21452946.n17.08. 


\title{
Roman Engineering, Public Works and Importance of Public Objects in Roman Law
}

\begin{abstract}
The skill and ability of the Romans in civil engineering and public works largely contributed to the establishment and success of their civilization. Many of the constructed works were built for the possibility of public use and enjoyment by its citizens, known as res publicae in usu publico.
\end{abstract}

Keywords: Roman Public Works, Civil Engineering, Public Utilities, Division of Objects, Public Objects, Objects outside Commerce, res publicae in usu publico.

\section{INTRODUCCIÓN: INGENIERÍA ROMANA Y OBRAS PÚBLICAS ${ }^{2}$}

La civilización de Roma fue, posiblemente, una de las más fructíferas y exitosas de la Antigüedad. Todo el conjunto de sus avances tecnológicos, sistemas de trabajos públicos (opera publica), arte, cultura, lengua, arquitectura y, por su puesto, derecho le llevaron a convertirse en el pueblo que hoy conocemos y, en su época, en el Imperio sinónimo de conquista y civilización. Naturalmente, sus avances y victorias militares marcaron una profunda e indeleble huella en la geografía y la historia de tres continentes: Europa, Asia y África.

Si se atiende a ese alto e importante número de avances tecnológicos y logros en lo que respecta a trabajos de orden público, los más grandes logros romanos los encontramos en sus acueductos, vías o calzadas, cloacas, puentes, túneles, edificios públicos tales como teatros, anfiteatros, circos, termas, baños, fuentes, arcos de triunfo, bibliotecas, etc.

A lo largo del mundo romano una cantidad enorme de grandes proyectos concernientes a obras públicas alteraban -en un primer momento-y disfrutaban con posterioridad millones de habitantes del Imperio. A modo de ejemplo, Augusto, ya emperador, decidió terminar algunos de los proyectos iniciados por su padre adoptivo, Julio César. Así, basta recordar el antiguo Foro romano, al que Octavio añadió su nuevo espacio público, el Foro de Augusto, del cual se decía en aquellos tiempos que era la más bella estructura del mundo. También nos viene a la memoria el Campo de Marte, siendo transformado en una agradable zona urbana a la que acompañaban baños públicos, jardines, templos, fuentes y parques. En todas estas áreas era evidente la mano de Augusto, quien se aseguró de que todos ellos fuesen cosas de la ciudad, cosas públicas

2 Este estudio se ha desarrollado en el marco del proyecto con referencia DER2015-64317-P, del Ministerio de Economía y Competitividad. 
en público uso (res publicae in uso publico) obteniendo, a cambio, la certeza entre la población respecto de a quién se debía estar agradecido.

No es la finalidad de este trabajo hablar de todas y cada una de esas grandes creaciones con sello romano. Sin embargo, por su vital importancia, se va a prestar atención en los siguientes párrafos a dos de los antiguos y mayores logros de Roma: el acueducto y las calzadas.

El acueducto romano era un sistema de agua muy avanzado, con agua corriente, inventado por la civilización que nos ocupa. El acueducto consistía en un sistema de un flujo constante de agua, orientado al transporte de agua dentro y fuera de la ciudad. Este sistema también incluye una estructura compleja pero efectiva de alcantarillado que, sin ninguna duda, colaboró decisivamente a evitar numerosas enfermedades de la población. Antes de la aparición del mismo, los habitantes sufrían enfermedades como la malaria o el tifus por abastecerse a través de agua fangosa y contaminada. Con la llegada del acueducto romano se proporcionó agua para fuentes, baños y villas. En definitiva, la creación del acueducto encontró su éxito en la transformación de Roma en una ciudad mucho más sana y más avanzada tecnológicamente.

Este sistema de agua corriente y alcantarillado no fue superado en capacidad y operatividad hasta tiempos muy modernos.

Traslademos nuestra atención a las vías romanas. Cuando los romanos entraban en una nueva región o territorio, tras obtener la victoria en batalla y así poder anexionar un nuevo lugar para el Imperio, lo primero a lo que atendían, desde el punto de vista militar y también administrativo, era a la construcción de calzadas, puentes y, por supuesto, acueductos que abastecieran de agua a las tropas y la población. Esos, se podría afirmar, eran los primeros pasos en la romanización del lugar.

En un primer estadio, eran los militares los que construían las vías romanas, al igual que las fortificaciones y la mayoría de obras públicas. Su experiencia en el alzamiento de caminos, fortalezas y puentes les convertía en los agentes ideales de construcción.

Si la primordial finalidad de la aparición de una vía en Roma venía determinada por el uso, desplazamiento y velocidad de las legiones romanas a través de la misma, estos caminos también supusieron una puerta abierta al desarrollo del comercio, los viajes y el contacto con los más remotos puntos del Imperio (decenas de miles de kilómetros). La importancia de estas obras públicas es demostrada por el gran interés que pusieron las autoridades romanas en crear un rico y variado conjunto de normas que atendieran a su administración: establecimiento, fondos para elevarlas, construcción, cura (mantenimiento y cuidado), protección ante el mal uso o descuido, etc. La aparición del cursus publicus (correo al servicio de autoridades y, posteriormente, de uso civil), sin duda, fue una consecuencia de la buena construcción de esas vías de comunicación. Además, a lo largo de estos casi indestructibles caminos surgieron elementos decorativos, de recreo, hospedaje, etc. 
La construcción y mantenimiento de calzadas públicas se extendió por un período aproximado de siete siglos (en el año 312 a.C. se construye la primera gran calzada romana, la vía Apia), fueron, evidentemente, el descenso acusado en el nivel de las arcas y las amenazas más allá de las fronteras romanas los que determinaron su paralización o desuso.

Como en renglones previos se anunció para los acueductos, en nuestros días también podemos usar algunas calzadas romanas o se han trazado carreteras que discurren por las cercanías de vías romanas. Indudablemente, síntoma del buen hacer y trazado de los "ingenieros" romanos.

En resumen, la habilidad de los romanos en la ingeniería civil es uno de los motivos que contribuyeron en gran medida a la creación y longa existencia de su civilización y su imperio. Sus carreteras y puentes conectados y su loable sistema administrativo lograron que viajar fuera más fácil para los comerciantes romanos, soldados y ciudadanos. Sus templos y grandes edificios públicos embellecieron sus ciudades; de hecho, hoy muchos siguen en pie como testimonio de su grandeza.

Sin embargo, si tuviésemos que elegir entre toda su inmensa ingeniería posiblemente habría que seleccionar como elementos trascendentales el sistema de vías de comunicación y el de abastecimiento de agua a las ciudades de los romanos, a quienes distinguen como una civilización avanzada, moderna, que destaca sustancialmente entre otras de la Antigüedad clásica. Los acueductos y las vías, siendo las piezas más visibles y gloriosas del antiguo sistema hidráulico y viario, se alzan como un valeroso testimonio de la ingeniería romana. La capacidad en su construcción supone que algunas de estas estructuras antiguas todavía están en uso hoy en día en algunos lugares por los que hace dos mil años pasaron los romanos.

\section{LA CLASIFICACIÓN DE LAS COSAS: LAS RES EXTRA COMMERCIUM}

En el estudio que se presenta se tiene la intención de responder cuestiones como en qué tipo de cosa son encuadrables para los romanos ese tipo de bienes que se crean a través de opera publica que anteriormente se han presentado. Sin duda alguna lo indica su adjetivo "públicas", por lo que estamos en condiciones de adelantar que caen dentro de la categoría de las res publicae, como loca publica que son.

Pero, ¿qué son esas res publicae?

Un repaso a las conocidas clasificaciones de las res que se desarrollaron por los juristas romanos se impone en estos momentos.

De todos es conocido que cualquier realidad del mundo que nos rodea es susceptible de ser denominada como "cosa" y de pertenecer simultáneamente a varias de las distintas tipologías de estos elementos que se introdujeron en el derecho romano. Pues bien, para determinar el carácter de las vías, acueduc- 
tos, termas, jardines, teatros, etc. denominados públicos debemos atender a la clasificación que tiene su punto de mira en la opción de poder comercializar con la res.

Una de las clasificaciones más famosa y conocida para los romanos fue la que distinguía entre res quarum commercium non est o cosas extra commercium y res intra commercium. El jurista Gayo (Inst. II,1) optó por denominarlas -y así distinguirlas-cosas quae in nostro patrimonio sunt y cosas quae extra nostrum patrimonium babentur.

Gai., II.1: Superiore commentario de iure personarum exposuimos; modo videamus de rebus: quae vel in nostro patrimonio sunt vel extra nostrum patrimonium babentur.

La primera división aludida tiene su fundamento en la comercialidad, sobre la base de que el bien sea capaz o no de ser objeto de derechos y negocios patrimoniales privados.

D. 18.1.6 pr. (Pomp., 9 ad Sabinum.): Sed Celsus filius ait bominem liberum scientem te emere non posse nec cuiuscumque rei scias <probibitam, > alienationem esse: ut sacra et religiosa loca aut quorum commercium non sit, ut publica, quae non in pecunia populi, sed in publico usu babeantur, ut est Campus Martius ${ }^{3}$.

La creada por Gayo, en cambio, se centra en la situación de la cosa en relación al patrimonium. De todos modos, las cosas fuera del comercio, llámense de una forma u otra, son cosas que se sustraen de la disponibilidad privada, de ahí su inidoneidad para formar parte de un patrimonium privado.

Dentro del primer grupo que hemos mencionado emerge a su vez otra subdivisión: res extra commercium divini iuris y res extra commercium bumani iuris. Esta clasificación supone la summa divisio rerum para Gayo, y Justiniano la recoge en D. 1.8.1, al empezar el título De divisione rerum et qualitate.

Gai., II.2: Summa itaque rerum divisio in duos articulos diducitur: nam aliae sunt divini iuris, aliae bumani.

En el primer subgrupo se encuadran las res sacrae, las res religiosae y las res sanctae.

Gai., II.3: Divini iuris sunt veluti res sacrae et religiosae.

Gai., II.8: Sanctae quoque res, velut muri et portae, quodammodo divini iuris sunt.

$Y$ en el segundo subgrupo deben figurar las res communes omnium, las res publicae y las res universitatis.

Las res extra commercium divini iuris eran aquéllas destinadas a satisfacer exigencias de tipo religioso. Están fuera del comercio por mandato de la norma divina. Se clasificaban en res sacrae, res religiosae y res sanctae. Res sacrae son los bienes destinados a los dioses superiores, tales como templos, altares, bosques sagrados... Para adquirir tal carácter era necesaria la consagración pública.

Gai., II.4: Sacrae sunt quae diis superis consecratae sunt, religiosae, quae diis Manibus relictae sunt.

3 También atienden a la comercialidad de la cosa fragmentos como D. 18.1.34.1 (Paul., 33 ad ed.) y D. 30.39.9-10 (Ulp., 21 ad Sabinum). 
Res religiosae son las destinadas a los dioses Manes, como las tumbas, sepulcros, tierra donde descansa el cadáver, objetos dirigidos a la conservación y ornamento del difunto, etc. En este caso el mero deseo del particular era suficiente para que algo se convirtiese en res religiosa.

Las res sanctae son las que están colocadas bajo la protección de los dioses, por ejemplo las puertas y murallas de la ciudad.

Según d'Ors ${ }^{4}$, se produjo una aproximación de los bienes santos a las cosas públicas que se explica por los poderes que tenía el príncipe sobre las murallas y fortificaciones, que también eran objeto de una ceremonia inaugural ${ }_{i}$ fue realmente Justiniano quien convirtió en tripartita a la categoría de las res extra commercium divini iuris. En relación con esta interdependencia, Gayo, en otra obra (Epítome, II. 1.1), mantuvo que ciertas cosas que los antiguos llamaban sanctae -muros, foros, puertas, teatros, circos, etc.- eran cosas de derecho público. Sin duda, es una tipología algo especial, la de las res sanctae.

En cuanto a las res extra commercium bumani iuris, eran las cosas que quedaban sustraídas de la disponibilidad de los particulares - disponibilidad privadapor consideraciones de oportunidad social ${ }^{5}$; esta sustracción procedía de la prescripción de la norma positiva ${ }^{6}$. Gayo diferenció en la categoría de las res bumani iuris las res publicae y las res privatae. Justiniano, en sus Instituciones, catalogó como cosas extra commercium -alejándose del paradigma gayano- las res communes omnium, las res publicae, las res universitatis y las res nullius, especificando que la mayor parte de las cosas son de los particulares -res singulorum-. Comparando a ambos, se observa que una categoría desconocida para Gayo fue la de las res communes; las res publicae del jurista albergan a las res universitatis ${ }^{7}$; y las res nullius del emperador son las viejas res divini iuris de Gayo ${ }^{8}$.

\section{LAS RES PUBLICAE}

Una vez que conocemos el elenco de bienes calificados como res divini iuris, dentro de la categoría de cosas fuera del comercio de los hombres, es preciso centrarnos en la otra gran división denominada por Gayo res bumani iuris, cosas extra commercium por causas de derecho humano. Este grupo resulta de mayor

4 Álvaro d'Ors. Derecho privado romano, 1997, pp. 176 ss.; Gian Gualberto ArChI, "La summa divisio rerum in Gaio e in Giustiniano", en Studia et Documenta Historiae et Iuris, 1937, pp. 15 ss.

5 Antonio Guarino. Diritto privato romano, Napoli 1970, p. 339. Asimismo, Giovanni Pugliese, Istituzioni di diritto romano, Padova, 1986, pp. 467 ss.

6 En estos términos se expresa JuAN IGLESIAS, Derecho romano. Historia e instituciones, Barcelona, 1993, p. 207. Cesare SANFILIPPO. Istituzioni di diritto romano, Catania, 1964, p. 68, aclara desde su punto de vista que la exclusión de la disponibilidad privada procede de la publicatio, o porque vienen directamente adquiridas por el Estado como botín de guerra.

7 I. 2.1.6: Universitatis sunt, non singulorum veluti quae in civitatibus sunt, ut theatra stadia et similia et si qua alia sunt communia civitatum.

8 I. 2.1.7: Nullius autem sunt res sacrae et religiosae et sanctae: quod enim divini iuris est, id nullius in bonis est. 
relevancia que el anterior para nuestro trabajo pues en el mismo se encuentra la subclasificación que hace referencia a la mayoría de construcciones resultado de obras públicas.

Como ha quedado expuesto, en las Instituciones de Justiniano (2.1 pr.) las res publicae se oponen a las res communes omnium y a las res universitatis, siendo las tres tipos de res extra commercium bumani iuris.

Gayo (II.9) no conoce las res communes omnium. Se refiere a las res publicae y a las universitatis dentro de lo que él llamó res quae extra nostrum patrimonium babentur ${ }^{9}$.

Etimológicamente, res publicae hace referencia a res populi, a cosa del pueblo romano (res publicae populi Romani). Cosas públicas son las que no pertenecen a ningún privado sino a la colectividad, a la comunidad organizada en Estado, ya que están destinadas al uso público, como un teatro, nos recuerdan Di Marzo ${ }^{10}$ o Volterra. Sin embargo, en opinión de Serrigny ${ }^{11}$ no es tan fácil determinar lo que los romanos entendieron por cosas públicas ya que "los textos dejan bastante que desear" acerca del sentido atribuido por la civilización romana a la expresión "res publicae". Justiniano, en sus Pandectas, entiende por ellas las que se oponen a los bienes de los particulares y que son universitatum, sin distinguir si esta corporación es el propio Estado u otra congregación.

D. 1.8.1 pr. (Gaius, 2 Inst.): Hae autem res, quae bumani iuris sunt, aut publicae sunt aut privatae. Quae publicae sunt, nullius in bonis esse creduntur: ipsius enim universitatis esse creduntur. Privatae autem sunt, quae singulorum sunt.

En sus Instituciones el emperador opone las cosas que son de dominio público "nacional" a aquellas de dominio público municipal (I. 2.1 pr. y $§ 6$ de Rer. Div.). Se detecta que en algunas ocasiones consideran las cosas públicas como res nullius y que en otras, en cambio, están bajo el dominio del Estado -ya sea en situación demanial o patrimonial-: Quae publicae sunt, nullius in bonis esse creduntur.

I. 2.1.6: Universitatis sunt, non singulorum veluti quae in civitatibus sunt, ut theatra stadia et similia et si qua alia sunt communia civitatum.

Lo que era del Estado romano pertenecía también al ciudadano, quien disfrutaba de esos bienes en común con el resto de ciudadanos, a diferencia de las res privatae que las tenía exclusivamente para él. Fuenteseca dijo que "son cosas cuyo propietario es el Estado y, por tanto, no pueden ser objeto de propiedad privada, si bien los particulares pueden utilizarlas porque su destino consiste en el usus publicus, como las calles, plazas, teatros o baños públicos ${ }^{\prime \prime 2}$. Su fin se

9 Para autores como Volterra, el texto de Gayo no se ha podido reconstruir entero.

10 Salvatore di Marzo. Manuale elementare di diritto romano, Torino, 1954, concretamente p. 114 Generoso Melillo. "Interdicta e operis novi nuntiatio iuris publici tuendi gratia", Labeo, 1966, n. ${ }^{\circ} 12$, p. 188, quien mantiene: "Evidentemente, nel pensiero giuridico del III secolo l'identificazione di res publicae con il concetto di res appartenenti ad ognuno nei limite di un uso comune e normale".

11 Denis Serrigny. Droit public et administratif romain, Paris, 1862, t. I, p. 432.

12 Pablo FuEnteseCA. Derecho privado romano, Madrid, 1978, p. 100. En este sentido Max KaSER. Römisches Privatrecht, München, 1981, p. 81. 
centra en el interés público. En el mismo sentido se expresa Bonfante ${ }^{13}$, sobre la titularidad del Estado, al interpretar la definición de Gayo II.10-11:

Hae autem quae bumani iuris sunt, aut publicae sunt aut privatae. Quae publicae sunt, nullius videntur in bonis esse, ipsius enim universitatis esse creduntur. Privatae sunt quae singulorum bominum sunt.

Por su parte, Ortega ${ }^{14}$ las define como "aquellos bienes pertenecientes al pueblo romano".

Ante tal estado unánime de opiniones se puede llegar a la conclusión de que toda res publica es un bien en propiedad del pueblo de Roma que es usado o disfrutado por los ciudadanos. Sin embargo, esta deducción no es cierta en su totalidad. Ciertamente, también conocieron en Roma la clasificación de otro tipo de res publicae que, por el contrario, sí podían caer bajo el comercio, ser objeto de relaciones jurídicas patrimoniales y pasar del patrimonio estatal (o de la ciudad) al de cualquier privado; bienes destinados a sostener mediante los beneficios que proporcionaban los gastos del Estado: son las res publicae in patrimonio fisci, in patrimonio o in commercio cuya propiedad por parte del Estado o de la civitas no se diferencia sustancialmente en su contenido económico de las cosas de los privados. Resultan administradas por el gobierno estatal en cuanto quasi propriae et privatae principis sunt ${ }^{15}$. Fernández de Buján ${ }^{16}$ nos acerca un poco más a la diferenciación:

13 Pietro Bonfante. Corso di diritto romano, vol. II, La proprietà, Parte 1, Milano, 1966, pp. 75-78.

14 Antonio Ortega Carrillo de Albornoz. Derecho privado romano, Málaga, 2002, p. 99. Estos bienes, como después se tratará, caen dentro del ámbito de aplicación del interdicto $\mathrm{Ne}$ quid in loco publico vel itinere fiat.

15 Con la misma idea, PAOLO MADDALENA. Gli incrementi fluviali nella visione giurisprudenziale clásica, Napoli, 1970, p. 90; Antonio Ortega Carrillo de Albornoz. Derecho privado romano, cit., p. 99, indica a propósito de las mismas: "Aquellas de las que el Estado tiene la propiedad y administra como persona jurídica. Son bienes in commercio y, por ende, objeto de negocios jurídicos, pudiendo el Estado enajenarlos o arrendarlos para así contar con una fuente de recursos. [...] por ejemplo, las tierras y esclavos conquistados al enemigo y considerados como botín de guerra, los bienes confiscados a los particulares)". Vid. D. 18.1.72.1 (Pap., 10 Quaestionum) y D. 41.1.14 pr. (Nerat., 5 Membranarum). Cesare SANFILIPPo. Istituzioni di diritto romano, cit., p. 68, no cree aplicable la distinción moderna "bienes demaniales-bienes patrimoniales", y así sostiene: "Non vale nel diritto romano la distinzione odierna tra 'beni demaniali', che appartengono allo Stato ma sono da esso destinati al libero uso del popolo (strade, terme, fori), e 'beni patrimoniali', che costituiscono il vero e proprio patrimonio dello Stato, di cui questo si serve pel raggiungimento dei suoi fini. Nel diritto romano tanto le res in usu populi, quanto le res in pecunia populi sono esenti dalle regole del diritto privato". Vid. también Flaminio Franchini. s.v. "Strade pubbliche, private e vicinali", NDI, t. XII, 1940, Parte 1. a , p. 911 y ANTONIO PALMA, "Le strade romane nelle dottrine giuridiche e gromatiche dell'età del Principato", ANRW II, Berlin-New York: Walter de Gruyter, 1982, pp. 860 ss. en relación a la evolución del fiscus.

16 Antonio Fernández de Buján. Derecho público romano, Madrid, 2004, 7. a ed., pp. 224-225. Vid. en relación a este título la recensión de Juan Miguel Alburquerque, "A propósito del 'Derecho público romano' del Prof. Dr. Antonio Fernández de Buján", en Iuris tantum, Facultad de Derecho de la Universidad Anáhuac (México), 1997, n. ${ }^{\circ}$ 8, pp. 233-252; también este último autor, en La protección o defensa del uso colectivo de las cosas de dominio público: Especial 
Las res publicae son aquellas que pertenecen al pueblo, "publica sunt, quae populi romani sunt" nos dice Ulpiano. Se distinguieron en Derecho Romano dos tipos de res publicae, las res publicae in publico uso, que eran aquellos bienes de titularidad pública destinados al uso colectivo y gratuito para todos los miembros de la comunidad, por ejemplo, aguas públicas, minas públicas, vías públicas, puertos, jardines públicos, etc., y las res publicae in pecunia populi o in patrimonio populi o fiscales, que eran aquellas cosas públicas que producían beneficios (económicos) al Estado. Esta segunda categoría de cosas se caracteriza por estar sujeta a un régimen jurídico semejante al de los bienes de los particulares, por lo que podían ser objeto de negocios jurídicos.

Si se presta atención a la propiedad de las res in patrimonio fisci, resulta asimismo diferente a la de las cosas públicas en uso público: "En la República romana se entendía que la titularidad de las res in pecunia populi correspondía al aerarium, mientras que a partir del Principado la titularidad se le atribuye progresivamente al Fisco, de ahí la expresión de res in patrimonio fisci o res fiscales"17.

En la aclaración del siguiente fragmento del Digesto sobre la procedencia del interdicto Ne quid in loco publico fiat, queda establecida una vez más la distinción entre las dos clases de res publicae. Este interdicto es de aplicación exclusiva a las res publicae in usu publico y no a las res in patrimonio fisci:

D. 43.8.2.4 (Ulp., 68 ad ed.): Hoc interdictum ad ea loca, quae sunt in fisci patrimonio, non puto pertinere: in bis enim neque facere quicquam neque probibere privatus potest: res enim fiscales quasi propriae et privatae principis sunt. Igitur si quis in bis aliquid faciat, nequaquam boc interdictum locum babebit: sed si forte de bis sit controversia, praefecti eorum iudices sunt.

Es decir, Ulpiano no cree que este interdicto se refiera a los lugares que están en el patrimonio del fisco porque en ellos un particular no puede ni hacer cosa alguna, ni prohibirla. Y la razón es que los bienes fiscales son como propios y privados del príncipe. Así pues, si uno hiciere en ellos alguna cosa, no tendrá de ningún modo lugar este remedio interdictal, y si acaso hubiera respecto a ellos controversia, son jueces los prefectos de los mismos. La exclusión de los bienes encuadrados como patrimonio fisci del ámbito de atención del interdicto reflejado en D. 43.8.2 pr. revelaría, según Melillo ${ }^{18}$, que en el siglo III no habría

referencia a los interdictos de publicis locis (loca, itinera, viae, flumina, ripae), cap. I, 5, páginas en donde el autor se concentra en la esfera de actuación de los interdictos relativos a las cosas públicas sometidas a uso popular.

17 Antonio Fernández de Buján, Derecho público romano, cit., pp. 224-225.

18 Generoso Melillo. "Interdicta e operis novi nuntiatio iuris publici tuendi gratia", cit., p. 189. Sobre las nuevas categorías o clasificaciones de cosas que aparecen en el Bajo Imperio, vid. MANLIO Sargenti. "Le 'res' nel diritto del Tardo Impero", Labeo, 1994-1, n. ${ }^{\circ} 40$, pp. 309-324, son significativas sus palabras (pp. 312-313): "Delle antiche classificazioni resta viva solo la categoria delle res publicae, ma in un'accezione che non è piú né quella classica né quella adombrata dall'epitomatore gaiano. Mentre la genuina nozione romana era quella di res populi, nel senso specifico di res populi Romani, ed ancora un giurista tardo come Ulpiano avvertiva (D. 50.16.15): Bona civitatis abusive publica dicta sunt, sola enim ea publica sunt quae populi Romani sunt, mentre l'Epitome fa delle 
cambiado el concepto de "lugar público" desde que fue aclarado por Labeón en la edad augustea. El motivo se centra en que Ulpiano recogió la definición de "locus publicus" de Labeón.

Una vez planteadas las diversas realidades que se esconden tras la expresión "res publicae" es fácil preguntarse cómo se distinguía un tipo de bienes del otro si ambos eran cosas públicas. La respuesta ha de buscarse en adjetivos o epítetos específicos usados en una y otra categoría, o bien insistiendo en el uso o el valor patrimonial: loca publica quae non in pecunia populi sed in publico usu

res publici iuris una categoria indifferenziata, nella quale, con quella che l'Albertario definiva una balorda confusione, riassorbe anche le antiche res sanctae, ma non mostra di considerare compresi in essa soltanto $i$ beni delle città, questo è, invece, il significato che l'espressione (come pure quelle equivalenti) ba costantemente nel linguaggio delle costituzioni imperiali: res publicae civitatis... res publicae ad singulas quasque pertinentes civitates... possessiones publicae civitatum..., e cosí via. Va perduto, dunque, il piú ampio significato della categoría delle res publicae. E ciò è, del resto, naturale in un assetto politicocostituzionale qual è quello del tardo Impero, in un regime dei beni che ba come centro di imputazione non piú il populus Romanus, ma il patrimonio o i vari complessi patrimoniali imperiali, e non avrebbe piú senso parlare di res publicae come res populi, di patrimonio della collettività nel significato che questi termini e queste categorie avevano nella società repubblicana ed almeno in parte conservavano ancora nel regime del Principato". Por su parte, FilipPo VASSALli. "Sul rapporto tra le res publicae e le res fiscales", en Studi Senesi, vol. 25, 1908 (= Studi Giuridici, vol. II, Milano, 1960, pp. 3-8), p. 7, afirmó: "pur no negando che fino a un certo periodo del diritto romano si sia concepita una proprietà dell'universitas populi sulle cose genericamente qualificate come publicae, quindi senza distinguere fra quelle in patrimonio populi e quelle in usu publico, come attesterebbe il passo di Gaius, 2 Inst. (fr. I pr. D. I. 8), bisogna però riconoscere che, nel senso ristretto ultimo -quale apparisce nei giureconsulti contemporanei ai Severi, e nella legislazione giustinianea-, le res publicae non implicano più la concezione di una proprietà del populus Romanus, nè quindi quella sua subiettività giuridica che in ogni senso vediamo definitivamente eclissarsi nel tempo dei Severi, assorbita in quella dell'imperatore e del suo fiscus [... ] nell'ordinamento dello Stato a un certo momento il populus non fu più soggetto di diritti patrimoniali". Con este desarrollo indicado por Vassalli finalmente serían consideradas como res publicae las cosas exclusivamente destinadas al uso público, adquiriendo de este modo un contenido objetivo. Cfr. las diferentes ideas de la doctrina en torno a esta temática con autores como Giuseppe BranCA. "Le cose extra patrimonium humani iuris", en Annali Triestini, 12, 1941, 3-248, p. 53; Giuseppe Grosso. Corso di diritto romano. Le cose, Torino, 1941, pp. 88 ss.; PIETRO Bonfante. Corso di diritto romano II, La proprietà, Parte 1, cit., pp. 78 ss.; GINO SEGRÈ. Corso di diritto romano. Le cose, la proprietà, gli altri diritti reali ed il posseso I, Torino, 1927, pp. 75 ss.; GAETANO SCHERILlo. Lezioni di diritto romano, Le cose I, Milano, 1945, 89 ss.; RicCARDO ORESTANO. Il problema delle persone giuridiche in diritto romano, Torino, 1968, pp. 296 ss. Por último, ANTONio PALma. "Le strade romane nelle dottrine giuridiche e gromatiche dell'età del principato", cit., p. 858, resume brevemente la teoría de Orestano acerca de las relaciones de pertenecia que los romanos no reconducían al populus, entendido como centro autónomo de referencia de las mismas: así, se aplicarían diversos criterios que emergen de las fuentes: 1) Una consideración objetiva de la relación de pertenecia en el sentido de que la calificación de publicus se concibe como una cualidad inherente a las cosas mismas, una condición objetiva y perpetua que tienen de por sí o sobre la base de normas positivas o consuetudinarias o, por último, por la actividad de un magistrado investido de ius publicandi. 2) También a veces las relaciones de pertenencia se refieren a la totalidad de los miembros de la comunidad considerados en concreto, uti cives. 3) Y una tercera concepción con la que algunas cosas vienen consideradas como centros autónomos de referencia de las relaciones jurídicas. 
babentur-D. 18.1.6 pr., a propósito del Campo de Marte-; publicae quae publicis usibus destinatae sunt, publica-res-quae usibus populi perpetuo exposita sit -I. 3.19.2-; ea quae in patrimonio sunt populi-D. 41.1 .14 pr. -; loca publica quae privatorum usibus deserviunt iure scilicet civitatis... ${ }^{19}$.

En este orden de ideas, Volterra aclara perfectamente:

... non tutte le res publicae sono però extra commercium: fra esse bisogna distinguere: 1) quelle cose che servono a bisogni collettivi, alla soddisfazione dei quali provvede lo Stato quale tutore di interessi pubblici, e che perciò sono sottratte al commercium e sono quindi inalienabili (come le strade consolari, le saline, gli edifici destinati ad una pubblica funzione, quali i fori e le basiliche, i fiumi pubblici, ecc.); 2) quelle cose che servono al soddisfacimento di bisogni individuali, le quali sono in commercio, cioè oggetto di negozi giuridici e pertanto alienabili e di cui il populus Romanus, in quanto persona giuridica, ba la proprietà (come ad. es. gli schiavi pubblici, gli oggetti mobili ed inmobili già appartenenti a privati e che sono passati al populus Romanus quale bottino di guerra, o in seguito a confische o condadde, ecc.).

Las primeras en haber sido expuestas son las que interesan en la presente investigación, las res publicae in usu populi.

Habiendo dejado bien claros los rasgos que muestran las res publicae in usu publico desde un punto de vista técnico (son las cosas del pueblo romano, del Estado quae publico usui destinatae sunt), se cree conveniente, antes de pasar a otra categoría, profundizar un poco más en este tipo de bienes por estar comprendidos entre ellos los elementos protagonistas de nuestro trabajo: las vías, cloacas, acueductos, plazas, jardines, circos, etc.

Se suelen citar como ejemplos de cosas públicas en uso público los ríos perennes, las riberas de los ríos, los puertos, las plazas, los foros, los teatros, jardines, etc., y, cómo no, las calles o vías. La pertenencia a la colectividad

19 Vid. D. 18.1.6 pr. (Pomp., 9 ad Sabinum); D. 43.8.2.4-5 (Ulp., 68 ad ed.); D. 18.1.72.1 (Pap., 10 Quaestionum), en los que se individualiza la categoría de las res publicae in usu publico. EDOARDO VOlTERRA. Istituzioni di diritto privato romano, Roma, 1972, p. 280, a este respecto afirma que los juristas romanos, no teniendo términos diversos para indicar una categoría u otra, mostraron perfectamente ser conscientes de la distinción. Y a propósito de esta distinción, el insigne profesor de la Universidad de Roma nos recuerda que en época republicana la administración y magistrados competentes en sede de res in publico usu y res in patrimonio fisci son diferentes; al censor le pertenecía el mantenimiento y vigilancia de las cosas públicas en uso público (calles, puertas, ríos, acueductos...), mientras que al cuestor le correspondía la administración del aerarium (el censor también administraba el ager publicus o patrimonio inmobiliario del Estado). Con idéntica exposición se muestra Giuseppe Grosso. Corso de diritto romano. Le cose, cit., pp. 116 ss. En cualquier caso, continuando con la exposición de este último autor mencionado (p. 128), "La visione delle categorie generali, per diritto romano, non debe mai prescindere dalla concretezza storica e giuridica delle singole figure. In questo campo bisogna soprattutto tener conto dei diversi punti di vista, del vario modo in cui essi si intrecciano e si evolvono, che rende la materia complessa e oscillante". Por último, sobre la confirmación de la doctrina consagrada en torno a las res fiscales por Ulpiano, cfr. BASILE ELIACHEVITCH. La personnalité juridique en droit privé romain, Paris, 1942, pp. 40 ss. 
de las mismas resulta afirmada una vez más en: D. 43.1.1.pr. (Ulp., 67 ad ed.): De rebus bominum interdicta redduntur aut de bis, quae sunt alicuius, aut de bis, quae nullius sunt... Quae sunt alicuius, baec sunt aut publica aut singulorum. Publica: de locis publicis, de viis deque fluminibus publicis...

Y en D.43.8.2.1-5 (Ulp., 68 ad ed.): Hoc interdictum probibitorium est et tam publicis utilitatibus quam privatorum per boc prospicitur. Loca enim publica utique privatorum usibus deserviunt, iure scilicet civitatis, non quasi propria cuiusque, et tantum iuris babemus ad optinendum, quantum quilibet ex populo ad probibendum babet.

El disfrute de las res publicae in usu populi, en principio, no tiene carácter económico o patrimonial, ni para el particular ni para el Estado. Pero eventual o accidentalmente, si una explotación económica resulta posible, nada veta que el Estado se aproveche y la cosa asuma el aspecto de un bien patrimonial ${ }^{20}$.

Atendiendo al origen de las cosas destinadas al uso público, es frecuente interrogarse sobre las hipotéticas causas que provocan esa publicidad y posterior sometimiento al disfrute de la comunidad. Podría responderse, atendiendo a un sector doctrinal, que son res publicae por su propia naturaleza -demanio natural o necesario diríamos hoy-, o por voluntad del hombre -demanio accidental o arbitrario-. En este sentido se pronuncia Fernández de Buján ${ }^{21}$ al sostener:

... las res publicae in publico uso lo son o bien en virtud de un acto de publicatio, o bien por razón de su destino o utilización pública, o bien por causas naturales. La publicatio consistía en una ceremonia en virtud de la cual un bien se transforma en público y se destina a la utilización colectiva. Se correspondería con lo que hoy se denomina afectación de una cosa al uso público. La publicatio era un acto administrativo, cuya competencia estaba expresamente atribuida a magistrados determinados, mediante el cual la cosa quedaba por tanto afectada o destinada al uso público. Se entendía en otros supuestos que la cosa era pública por razones naturales o por naturaleza, lo que ocurría, por ejemplo, con los ríos perennes. Es la llamada afectación natural. Por razón de su destino o utilización pública se consideraban en ocasiones públicas determinadas cosas sin necesidad del acto formal de la publicatio, así por ejemplo, la mera apertura al público de una carretera suponía su carácter público, sin necesidad de formalidad de ningún tipo.

Sin embargo, otra corriente mantiene que el origen público nunca procede de la naturaleza del bien: la destinación al uso público siempre procede del Estado (o, si se quiere, del hombre), por declaración general de la ley o de un acto administrativo solemne como la publicatio - por la que la cosa queda in publicum relicta- llevado a cabo por un magistrado competente (D. 43.8.2.21 (Ulp., 68 ad ed.); Suet. Oct., 29); o bien por el uso público inmemorial o vetus-

20 Opinión unánimemente compartida por la doctrina, con autores como PieTro Bonfante. Corso di diritto romano, vol. II-1, cit., p. 83.

21 FernándeZ de Buján. Derecho público romano, cit., p. 226. 
$\operatorname{tas}^{22}$, institución de derecho público que constituye una presunción de antigua concesión justificada sobre la base del tiempo inmemorial del uso (no significa la adquisición de un derecho gracias a determinado y largo tiempo). Por tanto, no hay cosas que sean públicas por derecho natural, lo que hay es cosas públicas que el propio hombre crea o no crea él mismo. Tanto unas como otras adquieren la condición de res publicae porque el Estado así desea destinarlas al uso público o crearlas para dicho uso. Lo contrario sería confundir el origen natural del bien con el principio que le impone su finalidad de uso público. En terminología romana encontramos las res publicae iuris gentium ${ }^{23}$ (reconocimiento general y necesario de su cualidad de públicas) y las res publicae iure civitatis o secundum mores civitatis. En todo caso ambas necesitan de los actos anteriormente aludidos para su destinación al uso público ${ }^{24}$.

Concretamente, las vías o caminos públicos son obras del hombre, obras públicas (opera publica, res publicae), que son destinadas al uso de los ciudadanos. Para Bonfante, las vías públicas pertenecen a la categoría de las res publicae, mas añade concretamente res publicae iure civitatis, secundum mores civitatis ${ }^{25}$.

No parece demasiado clara la idea que se tuvo en Roma referente al derecho sobre las cosas en uso público. Arangio-Ruiz ${ }^{26}$ sugirió al respecto que oscilaron en aquella época entre la idea de una especie de condominio de todos los ciudadanos y el concepto publicístico de la soberanía territorial. Bonfante ${ }^{27}$, por su parte, no dedicó una especial atención a esta cuestión, calificándola como ociosa porque no se puede solucionar o saber con certeza si el Estado tenía un derecho de propiedad, o de vigilancia, o de soberanía sobre las cosas públicas.

Los loca publica, como parte de la familia res publicae, no pueden ser ocupados por nadie y algunos los incluyen dentro de las res nullius; más propiamente deberían decir nullius in bonis ya que, en realidad, nadie podía adquirir para su propia utilidad la propiedad y estaban, por otra parte, al servicio de todos o, lo que es lo mismo, al servicio del populus, de lo que les viene la adjetivación de 'publica'. La única excepción a este principio viene dada por las concesiones.

En todo Estado se debe conjugar los intereses públicos con los intereses legítimos de los particulares (utilitas publica-utilitas singulorum). Son dos exigencias difíciles de conciliar a veces. Dichos términos no son extraños al pensamiento

Vid D. 43.7 .3 (Ulp., 33 ad Sabinum).

Grosso. Corso di diritto romano. Le cose, cit., p. 193.

Juan Iglesias. Derecho romano. Instituciones de derecho privado, Barcelona, 1979, p. 231, habla de cosas que son públicas por naturaleza (como lo ríos perennes, el mar y la ribera del mar) y otras, construidas por el hombre, que adquieren tal condición mediante acto solemne de la pública autoridad-publicatio-. BONFANTE. Corso di diritto romano, vol. II-1, cit., p. 84, años antes, rechazó esta corriente aduciendo -como se lee en el texto principal-que siempre el hombre es, en última instancia, quien decide su carácter público.

Pietro Bonfante. Corso di diritto romano, vol. II-1, cit., p. 104.

Vincenzo Arangio-Ruiz. Istituzioni di diritto romano, Napoli, 1974, pp. 171-172.

Pietro Bonfante. Corso di diritto romano, vol. II-1, cit., pp. 105-106. 
político en Roma ${ }^{28}$ como, de hecho, ocurre con la mayoría de las instituciones, conceptos y principios que hoy están vigentes en todos los ordenamientos jurídicos de las naciones que conservan en su derecho la tradición romana. En la República, la garantía de los derechos esenciales del ciudadano era una de las máximas fundamentales -hasta el Bajo Imperio-. La salus rei publicae es la ley suprema y con el absolutismo llega incluso a incrementarse su papel. De este modo, encontramos la utilidad pública como una de las piedras angulares de la doctrina política romana.

La utilitas publica será, así, aquella del conjunto del pueblo, del conjunto de ciudadanos: utilitas civium, bominum, omnium, communis. Y también aquella de la cosa pública, utilitas rei publicae -de la comunidad de los ciudadanos-. O la del Estado como entidad autónoma y representado por sus servicios públicos que, en ocasiones, antepone sus utilidades particulares a los propios ciudadanos, sus beneficiarios en principio que acaban convirtiéndose en sus víctimas.

En la propia Grecia surgió el tema del interés colectivo y a los conceptos aplicados allí Roma se encargará de dotarlos de una fisonomía propia. El concepto de utilidad común aparece por primera vez en Cicerón, el cual emplea diversos términos para referirse a esta realidad. Equivale al bien común de la colectividad y debe inspirar la legislación, las medidas fiscales, etc.

Otros personajes contemporáneos de Cicerón no serán ajenos a esa realidad: Salustio, Tácito, Dión Casio o Frontino la tienen en cuenta en sus disertaciones o trabajos. El famoso arquitecto dirá que el acueducto es construido ex utilitate rei publicae, lo que nos hace concluir que, indudablemente, la construcción de calles, calzadas, anfiteatros, puertos, cloacas, etc. sirve a esa misma utilitas.

Vassalli ${ }^{29}$ no vaciló al apuntar que la expresión 'res publicae' no incluye siempre en las fuentes todos los bienes de pública pertenencia; la expresión sufre un proceso de determinación en sentido restrictivo, el concepto se estratifica en correspondencia con épocas diversas. La distinción fundamental entre res in patrimonio populi y res in usu publico, que da a las res publicae la máxima comprensión, cede frente a una nueva distinción mientras se han producido cambios en el organismo del Estado. "Lindagine comparativa dei testi permette di stabilire che appunto dall'età dei Severi nell'espressione res publicae non son più comprese res in pecunia, in patrimonio populi". Con los Severos queda absorbido dentro de la esfera del fisco todo cuanto interesa a la finanza pública y la expresión 'res publicae' queda relegada exclusivamente para las cosas que no pueden formar parte del comercio, que no tienen valor económico, que son de uso colectivo. Así, los loca publica en Ulpiano (D. 43.8.2.2) son típicamente aquellos que privatorum usibus deserviunt, iure scilicet civitatis, non quasi propria cuiusque y $_{\text {está completamente }}$

28 Jean Gaudemet. "Utilitas publica", en Revue Historique de Droit Français et Étranger, 1985, pp. 465-499.

29 VAssaldi. "Sul rapporto tra le res publicae e le res fiscales in diritto romano", cit., pp. 3-8. 
alejada de la mente del jurisconsulto la noción de otros lugares que tiempo atrás formaban el ager publicus. Estos son ahora in patrimonio fisci ${ }^{30} \mathrm{y}$ aparecen al lado de los loca publica como loca fiscalia ${ }^{31}$.

La misma acepción de la expresión "res publicae", en el sentido estricto de cosas en uso público, se halla en la clasificación de Marciano (D. 1.8.4.1). Los compiladores sancionaron el carácter de las res publicae que ya portaban en la jurisprudencia de los Severos: la denominación de "públicas" queda reservada a ciertas cosas cuyo uso es común a todos. Vassalli notó que "l'aggettivo 'pubblico', riferito a cose, ba acquistato un contenuto obiettivo, dato da note di scopo e di regime, più che dalla subietiva riferenza. Per questo poteron dirsi 'pubbliche' cose le quali non erano del populus, ma di altri pubblici corpi, e pure di privati". Y recuerda este autor que los compiladores justinianeos no tuvieron dificultad alguna para hablar de res publicae populi Romani et civitatium, porque por cosas "públicas" entendían en general las cosas destinadas al uso público, y estas podían ser tanto del Estado romano (populi Romani) como de los municipios.

Por otra parte, siguiendo con las teorías de Vassalli, este expuso que el uso público puede conceder la cualidad de "pública" a cosas en propiedad privada. Estos supuestos encierran textos en los que la denominación "público" es usada únicamente en vista de la pública destinación, a pesar de la pertenencia privada. Es lo mismo que se dice en D. 43.8.2.23 (Ulp., 68 ad ed.) al calificar de públicas a las vías de propiedad privada quae post consularem excipiunt in villas vel in alias colonias ducentes, en razón del uso que les es concedido a todos ${ }^{32}$.

En definitiva, a partir de los Severos en la jurisprudencia queda fijada una distinción fundamental entre las cosas que formaban los bienes del Estado, entre res in patrimonio fisci y res publicae -en el sentido exclusivo de res in usu publico estas últimas-. Las res fisci no son ya una subcategoría de las res publicae en general, junto con la otra subcategoría de res publicae in usu publico, sino que han pasado a crear su propia categoría, al lado de la de las res publicae-que equivalen a res in usu publico solamente-.

Por último, en el estudio del italiano se advierte que ya en el derecho justinianeo con la expresión "res publicae" se quiere indicar el servicio público inherente a la cosa, prescindiendo de cualquier referencia al sujeto populus, al menos por lo que respecta a su derecho de propiedad (la res publica-originariamente populica- no es tal en cuanto está en propiedad de la "universitas populi"). En las cosas públicas por antonomasia una referencia al pueblo romano queda,

30 Cfr. D. 43.8.4 (Scaev., 5 Responsorum)

31 Vid. D. 49.14.3.10 (Callistr., 3 de iure Fisci).

32 Filippo Vassalli. "Sul rapporto tra le res publicae e le res fiscales in diritto romano", cit., pp. 5 y 6 . Por ejemplo, se trata de públicos al hablar de la orilla de un río público y la isla en un río público -D. 41.1.65.1 (Lab., 6 Pithanon a Paulo epitomarum): ... in eo genere insularum, ripae flumini et litora mari proxima publica sunt, D. 43.12 .3 (Paul., 16 ad Sabinum): Flumina publica quae fluunt ripaeque eorum publicae sunt-. 
permanece y bien lo constata Ulpiano al decir "ea publica sunt, quae populi Romani sunt" (D. 50.16.15). Justiniano traerá esa definición a su compilación ${ }^{33}$.

\section{ELEMENTOS DIFERENCIADORES \\ DE LAS RES PUBLICAE IN USO PUBLICO}

Entre las características tradicionales de estos bienes se encuentran las que figuran a continuanción, siguiendo la enumeración que lleva a cabo Fernández de Buján ${ }^{34}$ :

a. Pertenencia al populus o a un ente público.

b. Régimen de uso regulado por el ente titular y abierto a todos los miembros de la colectividad. Todos los ciudadanos tenían el uso uti singuli. Este uso no le correspondía a cada uno a título de propiedad privada o de servidumbre "attiva" sobre la cosa pública, sino que le venía otorgado por su calidad de ciudadano y por derecho público "iure civitatis": loca enim publica utique privatorum usibus deserviunt, iure scilicet civitatis, non quasi propria cuiusque (D. 43.8.2.2).

c. Publicatio, destino natural o vetustas, en la caracterización como público del bien correspondiente.

d. Inalienable: el bien está fuera del comercio; su venta, al estar fuera del tráfico jurídico, era nula ${ }^{35}$.

e. Imprescriptible: el bien no puede ser adquirido por usucapión de un particular. Por este principio, el desuso de una vía pública no daba lugar a

33 VASSALLI. "Sul rapporto tra le res publicae e le res fiscales in diritto romano", cit., p. 8: "Tutto sta nel precisare il contenuto di questo rapporto. Il populus romanus qui appparisce come l'espressione riassuntiva dello Stato, ed è l'autorità dello Stato la sfera di volontà che domina e determina la destinazione de quelle cose. Anche nella monarchia assoluta si può in questo senso parlare del populus Romanus, perchè è l'imperium populi Romani che idealmente l'imperatore rappresenta ed esercita, non così si potrebbe parlare della sua subiettività patrimoniale".

34 Antonio Fernández de Buján. Derecho público romano, cit., p. 226.

35 Para la venta de cosas fuera del comercio vid. Biondo Biondi. "La vendita di cose fuori di commercio", en Studi in onore di Salvatore Riccobono nel XL anno del suo insegnamento, Palermo, 1974, vol. IV, pp. 19-57. Los bona civitatium destinados al uso público también quedaban excluidos de la usucapión. Vid. Lucio Bove. Ricerche sugli agri vectigales, Napoli, 1960, p. 171; Robin Evans-Jones y GeOfFrey McCormack. "The sale of res extra commercium in Roman Law", ZSS, n. ${ }^{\circ} 112$ (1995), pp. 330-351, especialmente p. 342: "Even by the high classical period the jurists bad not been prepared to recognise the validity of the contract of sale for the former class of res extra commercium. This is stated very clearly in a passage of Ulpian: 28 ad Sab. D. 18.1.22: Hanc legem venditionis "si quid sacri vel religiosi est, eius venit nihil" supervacuam non esse, sed ad modica loca pertinere. Ceterum si omne religiosum vel sacrum vel publicum venierit, nullam esse emptionem". Para la época justinianea, vid. pp. 348 ss. (e Inst. 3.23.5), en la que parece existir mayor duda al respecto. Cfr. Giambattista Impallomeni. "In tema di strade vicinali", en Scritti di diritto romano e tradizione romanistica, Padova, 1996, pp. 541-560, (p. 553, n. 56), sobre la posibilidad de la aplicación de la vetustas favorecedora a un particular, la cancelación de los efectos de la publicatio o del uso público, y sobre la ocupación de los subseciva per longum tempus. 
prescripción o a pérdida del derecho en perjuicio del Estado. Javoleno en D. 43.11.2 (Iav., 10 ex Cassio) presenta este asunto en los mismos términos: Viam publicam populus non utendo amittere non potest ${ }^{36}$. La imposibilidad de aplicar la institución de la usucapio también se presenta muy clara en D. 41.3.9 (Gai., 4 ad Edictum provinciale): Usucapionem recipiunt maxime res corporales, exceptis rebus sacris, sanctis, publicis populi romani et civitatum, item liberis bominibus.

f. Nulidad de estipulaciones, legados, servidumbres, etc., realizados sobre este tipo de cosas.

Y, por último, el civis gozaba del derecho a ejercitar acciones e interdictos para tutelar las cosas públicas en uso público; era un derecho que correspondía a todos los miembros de la comunidad. Scialoja ${ }^{37}$ les denominó "derechos públicos difusos" al ser públicos y pertenecer al individuo como miembro del pueblo; pero le corresponde a él y no al pueblo como un ente diverso y totalmente distinto de él. No se trata de un derecho público concentrado sino de un derecho público extendido entre todos los miembros de la comunidad. En realidad, lo que realmente se protegía o, si se desea, defendía, era el uso y disfrute de las res publicae por el particular, mediante la actio iniuriarum y diversos interdictos. Específicamente para las viae publicae e itinera publica se conoce un completo conjunto de medidas a tal efecto (D. 43.8, 10 y 11). El papel de este civis en la sociedad republicana, en la vida cotidiana, en el ámbito de la administración pública es un papel muy activo en lo que atañe a la defensa o cura de las res publicae in usu publico. Acciones populares e interdictos populares estarán en sus manos y constituirán un eficaz instrumento de poder, le otorgarán una importante responsabilidad en la tutela de este tipo de res $^{38}$. El

36 La expresión de Javoleno se considera superflua al ser algo absolutamente conocido y admitido. Es esta la causa que lleva a algunos a considerar que la vía pública a la que se está refiriendo Javoleno no era una vía en propiedad del Estado, sino una vía privada en uso público (considerada gracias a ese uso común como pública).

37 Vittorio Scialoja. Prefazione alla traduzione de Le azioni popolari romane, de Bruns, en AG, XXVIII, 1882 (= Studi giuridici, I, 1, Roma, 1933, pp. 108 ss., en concreto, p. 117).

$38 \mathrm{Al}$ menos durante la República ostentará un papel predominante y compartido con las tareas de los magistrados, como pudieron ser los censores y los ediles, los quatuorvirei vieis in urbem purgandis -ya en su último siglo-, e incluso personajes a los que se confiaron especiales tareas (Julio César, siendo edil curul, tuvo que encargarse de la cura de la vía Apia en el año 65 a. C.). Sin embargo, en el Imperio se producen algunos cambios que se prolongarán y acentuarán en el Dominado: comienza a crecer el número de curatores con competencia específica sobre las res in usu publico (es el caso, p. ej., de los curatores viarum), se redimensiona el ámbito de aplicación de los interdictos populares y se reduce el espacio del ciudadano para ejercer la tutela de las cosas en uso público. ANDREA DI PORTO. "Interdetti popolari e tutela delle res in usu publico", en Diritto e processo nella esperienza romana, Atti del seminario torinese (4-5 dicembre 1991) in memoria di Giuseppe Provera, Napoli: Jovene, 1994, p. 520, supo expresar perfectamente esta situación: "Al 'modello' repubblicano si va così progressivamente sostituendo un 'modello' imperiale nell'ambito del quale, como si è visto, attraverso un passaggio dal 'popolare' al 'pubblico' (nel senso di pertinente all'amministrazione imperiale), ai magistrati viene ormai riservata la cura di talune res in usu publico (tendenzialmente, si direbbe, le più importanti), 
actor-civis defiende el interés del pueblo, de la comunidad y, a la vez, defiende el propio. Y aunque el propio particular no se encuentre especialmente interesado, podrá evitar un acto que amenace con provocar algún impedimento del uso público, o hacer que se revoque un acto que ya haya ocasionado tal obstáculo. Diferencia notable con las regulaciones de nuestros días por las que la autoridad administrativa tutela el uso público de oficio, como por ejemplo la vialidad, aguas públicas, etc.

En la edad imperial se irá sustituyendo poco a poco el populus por el princeps, entendido como persona física.

Como bien indica Di Porto, "gli interdetti popolari sono introdotti in relazione precisamente a quella categoria di res publicae, che, per il fatto di essere soggette all'immediata utilizzazione dei cives in quanto tali, vengono dai giuristi classificate come res in usu publico. E di tali res gli interdetti popolari caratterizzano il regime, differenziandolo dalle altre res publicae ${ }^{\prime \prime 39}$.

El derecho a usar un lugar público fue definido y determinado dentro de unos confines racionales por Donello: "Est usus quidem locorum publicorum ita publicus, ut sit singulorum, id est quo quilibet ex populo sibi suoque jure privatim locis publicis uti possit, dum publicus usus eo facto non impediatur ${ }^{\prime \prime 4}$. Asimismo, hay otras indicaciones claras que muestran el destino principal de los acueductos, calzadas, puentes, jardines, fuentes, teatros, bibliotecas, etc., que no es otro que el empleo del pueblo:

D. 43.7.1 (Pomp., 30 ad Sabinum): Cuilibet in publicum petere permittendum est id, quod ad usum omnium pertineat, veluti vias publicas, itinera publica: et ideo quolibet postulante de bis interdicitur.

D. 39.2.24.pr. (Ulp., 63 ad ed.): Fluminum publicorum communis est usus, sicuti viarum publicarum et litorum. In bis igitur publice licet cuilibet aedificare et destruere, dum tamen boc sine incommodo cuiusquam fiat.

mentre al civis viene ancora mantenuto un ruolo attivo, ma appunto limitatamente ad alcune, poche res in usu publico. Il cittadino, si potrebbe dire, conserva l'usus, ma senza più il potere". Sobre la tutela de los loca publica y, en general, res in usu publico vid., entre otras, la interesante y profunda obra de un especialista en el tema como es Juan Miguel AlbuRQUERQUE. La protección o defensa del uso colectivo de las cosas de dominio público: Especial referencia a los interdictos de publicis locis (loca, itinera, viae, flumina, ripae), Madrid, 2002. En cuanto a remedios procesales populares, vid. también Andrea Di PORTO. "Interdetti popolari e tutela delle res in usu publico", cit.; CARLO Giorgio Bruns, "Le azioni popolari romane", trad. Scialoja, AG, XXVIII, 1882 (= Scialoja, Studi giuridici. Diritto romano, I, Roma, 1933), Carlo FadDa. L'azione popolare. Studio di diritto romano ed attuale, I. Diritto romano, Torino, 1894; José LuIs MuRGA. "Las acciones populares en el municipio de Irni", BIDR, LXXXVIII, 1985, pp. 209 ss.; ID. "Las acciones populares en la lex Coloniae Genetivae Juliae", en Seminarios complutenses, I, 1990, pp. 103 ss.; ID., "La popularidad de las acciones en las leyes municipales de la Bética", RIDA (1991), pp. 221 ss.

39 AndREa di Porto. "Interdetti popolari e tutela delle res in usu publico", cit., p,p, 513.

40 De jure civ., lib. 2, cap. v, 1 12. Vid. Juan Miguel Alburquerque, "Hugo Donellus", en Juristas Universales, vol. 2, Juristas Modernos, Marcial Pons, 2004, ed. R. Domingo ed., pp. 232 238. 
Ese uso se debe extender en la medida en que no cause un incommodum al resto de personas que también emplean esos bienes, es decir, se impone un uso prudente ${ }^{41}$. Por consiguiente, pasar por la vía con carros o coches, alzar a los lados edificios con puertas y ventanas, servirse del plano vial para entrar y salir cómodamente de la casa u otros usos similares no son actos de tolerancia concedidos por la autoridad pública y revocables según su beneplácito, sino verdaderos derechos del ciudadano, iure civitatis, y que tienen su fundamento en la misma naturaleza de los bienes destinados a utilidad pública, entre los cuales se encuentran, entre otros muchos, los presentados en la introducción. Los particulares tienen (como se avisó antes) el uso de los loca publica en cuanto son ciudadanos -iure civitatis-, no como si fuesen propios de cada uno o, en otras palabras, sin que ninguno pueda considerarse propietario o poseedor a título particular; y cualquiera -quantum cuilibet ex populo- del pueblo tiene derecho para impedir que se perturbe ese uso $^{42}$. Baste para reafirmar nuestras explicaciones sobre la imputación a la totalidad de los ciudadanos del uso de los lugares públicos las elocuentes palabras -una vez más- de Ulpiano:

D. 43.8.2.1-5 (Ulp., 68 ad Ed.): Hoc interdictum probibitorium est et tam publicis utilitatibus quam privatorum per boc prospicitur. Loca enim publica utique privatorum usibus deserviunt, iure scilicet civitatis, non quasi propria cuiusque, et tantum iuris babemus ad optinendum, quantum quilibet ex populo ad probibendum babet.

Como paso final para acabar nuestro acercamiento a las res publicae in usu publico se considera pertinente realizar una concisa mención a un conjunto de muy distintos bienes que se catalogan de tal manera. No es necesario probar que son numerosísimos, cosa evidente.

Algunas de las res publicae in usu publico arropadas por la tutela interdictal popular y que encontramos frecuentemente en la vida romana (y en el presente) son:

- Los lugares quae publico usui destinata sunt.

D. 43.8.2.3 (Ulp., 68 ad ed.): Publici loci apellatio quemadmodum accipiatur, Labeo definit, ut et ad areas et ad insulas et ad agros et ad vias publicas itineraque publica pertineat.

Son los teatros, circos, termas, bibliotecas, puentes, baños, puertos, anfiteatros, foros, fuentes, etc.

- Las viae publicae. Quizá se introdujo la mención de este elemento después de una primera fase en la que las vías públicas eran protegidas con el interdicto relativo a los loca publica en general, que correspondía a las cosas del punto anterior. Junto a las viae publicae se alude bastantes veces a los itinera publica (D. 43.8.2.20 y D. 43.8.2.35). Pensamos que la importancia de estas líneas

41 Vid. Antonio Palma. Iura vicinitatis. Solidarietà e limitazioni nel rapporto di vicinato in diritto romano dell'età classica, Torino, 1988, pp. 172 ss.

42 Vid. Riccardo ORESTANO. Il probleme delle persone giuridiche in diritto romano, pp. 310 ss. 
de comunicación pudo ser la razón que dio lugar a la creación pretoria de un remedio interdictal propio para ellas.

- Los flumina publica y sus orillas.

- Las cloacas públicas.

- Los acueductos.

\section{LAS RES UNIVERSITATIS}

Si este tipo de bienes -res publicae in usu publico- pertenece a los habitantes de una comunidad, como los municipios, colonias, ciudades... las civitates en definitiva y tienen análogo destino se denominan res universitatum ${ }^{43}$ en el elenco de Marciano y Justiniano (I. 2.1 pr. y D. 1.8.2), aunque antes seguían recibiendo el nombre de res publicae. En la lex Tarentina, lex Antonia de Thermessibus, la Sententia Minuciorum, Tabula Heracleensis y la lex coloniae Genetivae Inliae de la época de César aún se les llama res publicae; después, ya en época de los Flavios se les da el nombre más genérico de res communes o communia (p. ej., en la lex Salpensana y la lex Malacitana). Los juristas clásicos se encargaron de decir que aplicar el término "público" a los bienes de la ciudad era abusivo ${ }^{44}$ :

D. 50.16 .15 (Ulp., 10 ad ed.): Bona civitatis abusive "publica" dicta sunt: sola enim ea publica sunt, quae populi Romani sunt.

D. 50.16.16 (Gai., 3 ad Edictum provinciale): Nam "publica" appellatio in compluribus causis ad populum Romanum respicit: civitates enim privatorum loco babentur ${ }^{45}$.

D. 50.16 .17 (Ulp., 10 ad ed.): Inter "publica" babemus non sacra nec religiosa nec quae publicis usibus destinata sunt: sed si qua sunt civitatium velut bona.

43 Sobre esta clasificación vid., entre los numerosos estudiosos del tema, Pietro Bonfante. Corso di diritto romano, vol. II-1, cit., pp. 105 ss.; Luigi Aru y Riccardo Orestano. Sinopsis de derecho romano, Madrid, 1964, p. 100; Giuseppe Grosso. Corso di diritto romano. Le cose, cit., pp. 115 ss.

44 A fin de evitar equívocos también con estos textos, estos juristas niegan que las cosas in usu publico pudieran ser calificadas correctamente como "públicas", a no ser que pertenecieran al pueblo romano. Cfr. Antonio Palma. "Le strade romane nelle dottrine giuridiche e gromatiche dell'età del principato", cit., p. 858. Lex Salpensana, 26, c. 2,3, en FIRA, 1, 206 (n. 23) y Malacitana, 60 (rubrica); 60,c. 3,$31 ; 63$, c. 4,$13 ; 64$, c. $4,21.32$, en FIRA, 1,$213 ; 215$, 216 (n. 24); lex Tarentina, 9,(1),1; (2),10.17.22; (4),37; (5),40 en FIRA, 1, 167 ss. (n. 18); la Sententia Minuciorum, 23,25 en FIRA, 3, 507 (n. 163); Frontin. Grom. 20,7; 54.16 (Lachmann).

45 Pietro Bonfante. Corso di diritto romano, vol. II-1, cit., p. 105, evoca la condición promiscua del empleo de esos términos referidos a los bienes de las ciudades. Incluso en el lenguaje de la ley o edictal aparecen ambigüedades al respecto. Por su parte, Lucio Bove. Ricerche sugli agri vectigales, cit., p. 170, se sitúa en la misma línea de opinión, recordando el "uso abusivo e indudablemente difuso entre los jusristas" del término res publicae. Para la misma cuestión, vid., entre otros, Giuseppe Grosso. Corso de diritto romano. Le cose, cit., pp. 116 ss.; y GiambatTista Impallomeni. "In tema di strade vicinali", cit., p. 544, n. 13 y 14, en referencia a las leyes municipales. 
La partición según el concepto de res publicae en sentido riguroso -como cosas populi romani- se advierte bien en D. 1.8.6.1 (Marc., 3 Institutionum) [= I. 2.1.6]: Universitatis sunt, non singulorum veluti quae in civitatibus sunt theatra et stadia et similia, et si qua alia sunt communia civitatum.

En cualquier caso, entre los lugares y bienes de los municipios se contaban y denominaban como públicos las cosas sacras, religiosas o destinadas al uso público pues el municipium reflejó en su estructura, en pequeña esfera, la organización del Estado romano ${ }^{46}$. En el mismo sentido se sitúa Grosso, reconociendo que, sea como sea, las vías de la ciudad o las que a la misma sirven son cosas destinadas al uso público, tal y como los fora, theatra, basilicae, stadia... ya se incluyan dentro de la categoría de res publicae o dentro de la de res communes civitatium.

Gai., II, 11: Quae (res) publicae sunt, nullius videntur in bonis esse, ipsius enim universitatis esse creduntur.

La expresión "nullius" señala que no son privatae, son extra nostrum patrimonium en la terminología del mismo Gayo adoptada en un tiempo posterior.

\section{LAS RES COMMUNES OMNIUM}

En cuanto a las res communes omniun, esta tipología presenta un marcado carácter filosófico ${ }^{47}$ y no resultó ignorada por los juristas clásicos pues Marciano en el siglo III la refiere en sus Instituciones (D. 1.8.2.1), quizá bajo influencia de concepciones escolásticas de su tiempo. El derecho natural es el que parece influir, por tanto, en la introducción de esta ordenación. Justiniano hace suya la distinción elaborada por Marciano y la inserta en sus Instituta.

I. 2.1.1: Et quidem naturali iure communia sunt omnium baec: aer et aqua profluens et mare et per boc litora maris.

Son bienes no económicos que no deberían considerarse como "cosas" desde el punto de vista jurídico, como bien las obvió Gayo. Son gratuitos, no permutables, entes que son útiles e indispensables para la vida, disponibles en cuanto su cantidad es superior a las necesidades de los hombres (aer, aqua profluens, mare, etc.). Son profundas las dificultades para armonizar esta categoría con la de res publicae, teniendo además en cuenta que algunas de estas res communes omnium figuran en determinados textos de jusristas romanos como res publicae. 


\section{CONSIDERACIONES FINALES Y LEGISLACIÓN CONTEMPORÁNEA}

La materia relacionada con la ingeniería civil romana y las obras públicas alberga cuestiones realmente amplias e interesantes, siendo especialmente determinante la historia y régimen de dos bienes públicos tan trascendentales como los acueductos y las vías o calzadas.

En la actualidad existe una mayor separación -por no decir total- entre las cosas del Estado y la participación del ciudadano en ellas, de manera que la perfecta identidad de intereses en el mundo romano es difícil apreciarla hoy en día, pues el romano se sentía plenamente integrado en el Estado, era parte del mismo (de ahí el empleo del término "populus" para referirse a esa realidad que, como se sabe, desde el siglo XVI, empieza a configurarse como el Estado Moderno). Y es que la concepción del Estado Moderno es bastante distinta a la que se tenía en la Antigüedad ${ }^{48}$.

La noción jurídica contemporánea de "obras públicas" aclara que son aquellas construcciones promovidas por un organismo administrativo, con el fin inmediato de satisfacer una necesidad pública. La obra ha de encaminarse a la búsqueda de un interés público, interés que es el que determina que se encuentre bajo el manto competencial de la Administración, y que respecto a las mismas la Administración, para asegurar o garantizar ese uso o aprovechamiento común, pueda llegar a poner en marcha alguna de las prerrogativas de las que está investida. La procura de un interés social que encierra toda obra pública es la que conduce a su demanialización.

En esta exposición ha quedado demostrado que la división o clasificación de las cosas que se realizó en derecho romano, referida a las cosas públicas, ha ejercido una profunda influencia en la tipología actual de bienes de la misma naturaleza. Así, en el Código Civil español (capítulo III, "De los bienes según las personas a que pertenecen") es fácil observar las afinidades e incluso coincidencias absolutas a propósito de la división de bienes que sostiene ${ }^{49}$ :

Artículo 338.

Los bienes son de dominio público o de propiedad privada.

Artículo 339

Son bienes de dominio público:

48 Vid. al respecto Rudolf VON IHERING. Der Zweck im recht, I, Leipzig, 1884, trad. ital. a cargo de M. Losano, Lo scopo nel diritto, Torino, 1972, pp. 338 ss.

49 ANTONIO FERNÁNDEZ DE BuJÁN corrobora tal afirmación al indicar que "las res publicae in pecunia populi o in patrimonio populi of fiscales [...] se corresponden con el actual concepto de bienes patrimoniales del Estado. Las res publicae in publico usu constituyen a su vez el antecedente de los hoy denominados bienes demaniales". 
1. ${ }^{\circ}$ Los destinados al uso público, como los caminos, canales, ríos, torrentes, puertos y puentes construidos por el Estado, las riberas, playas, radas y otros análogos.

2. ${ }^{\circ}$ Los que pertenecen privativamente al Estado, sin ser de uso común, y están destinados a algún servicio público o al fomento de la riqueza nacional, como las murallas, fortalezas y demás obras de defensa del territorio, y las minas, mientras que no se otorgue su concesión.

Artículo 340.

Todos los demás bienes pertenecientes al Estado, en que no concurran las circunstancias expresadas en el artículo anterior, tienen el carácter de propiedad privada.

Artículo 341.

Los bienes de dominio público, cuando dejen de estar destinados al uso general o a las necesidades de la defensa del territorio, pasan a formar parte de los bienes de propiedad del Estado.

Artículo 342.

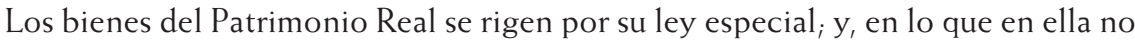
se halle previsto, por las disposiciones generales que sobre la propiedad particular se establecen en este Código.

Artículo 343.

Los bienes de las provincias y de los pueblos se dividen en bienes de uso público y bienes patrimoniales.

Artículo 344.

Son bienes de uso público, en las provincias y los pueblos, los caminos provinciales y los vecinales, las plazas, calles, fuentes y aguas públicas, los paseos y obras públicas de servicio general, costeadas por los mismos pueblos o provincias.

Todos los demás bienes que unos y otros posean son patrimoniales y se regirán por las disposiciones de este Código, salvo lo dispuesto en leyes especiales.

Artículo 345.

Son bienes de propiedad privada, además de los patrimoniales del Estado, de la Provincia y del Municipio, los pertenecientes a particulares, individual o colectivamente.

La base normativa con la misión de regular el dominio público se localiza en el artículo 132 de la Constitución española de 1978, lo indicado en los artículos 338 y siguientes del Código Civil, las legislaciones patrimoniales del Estado o comunidades autónomas, las leyes de las entidades locales, normas referentes a aguas, puertos, costas, minas, etc.

Reza la Constitución española, artículo 132: 
1. La ley regulará el régimen jurídico de los bienes de dominio público y de los comunales, inspirándose en los principios de inalienabilidad, imprescriptibilidad e inembargabilidad, así como su desafectación.

2. Son bienes de dominio público estatal los que determine la ley y, en todo caso, la zona marítimo-terrestre, las playas, el mar territorial y los recursos naturales de la zona económica y la plataforma continental.

3. Por ley se regularán el Patrimonio del Estado y el Patrimonio Nacional, su administración, defensa y conservación.

Ciertamente, son numerosas las definiciones que han aparecido en torno al dominio público ${ }^{50}$, pues es esencialmente un concepto de construcción doctrinal. Desde el punto de vista del derecho administrativo contemporáneo cabría decir que son aquellas propiedades administrativas afectadas a la utilidad pública; por consiguiente, gracias a esta afectación (una cosa queda destinada a un fin de interés público - uso o servicio público- y adquiere la condición jurídica peculiar de bien de dominio público) están sometidas a un régimen especial de utilización y protección.

Estas propiedades, al igual que en derecho romano, están excluidas del tráfico jurídico privado, se incorporan al demanio a partir del régimen de la afectación (recuérdese la publicatio), son susceptibles de mutación demanial y, evidentemente, de desafectación o cesación de demanialidad.

Los bienes de dominio público, asimismo, se encuentran afectos al uso y servicio públicos, e incluso al fomento de la riqueza nacional. Por último, ya que les caracteriza su extracomercialidad, son ajenos al régimen jurídico de la propiedad de derecho común. Precisamente como consecuencia de esa situación de res extra commercium son cosas inalienables, imprescriptibles e in-

50 Antonio FernándeZ de Buján. Derecho público romano, cit., p. 225. Realizando un breve recorrido acerca de la evolución del dominio público, el profesor de la Universidad Autónoma de Madrid agrega (ob. cit., loc. cit.) que "la idea del dominio público se configura, por tanto, básicamente en torno a las res publicae in publico usu romanas, si bien la elaboración conceptual y dogmática de dicha idea se inicia en la Edad Media y se desarrolla en el Derecho consuetudinario francés, e incluso hay que esperar a la Revolución Francesa y al Código de Napoleón para que se consagre la expresión dominio público, de donde pasa a nuestro Código Civil y a la legislación europea en general. La evolución producida a propósito de la institución del dominio público es significativa para argumentar, frente a la opinión mantenida por algunos estudiosos, que en el Derecho actual se conservan términos o expresiones jurídicas arrastradas desde el Derecho Romano, pero que tienen en la actualidad una significación diferente a la que tuvieron en sus orígenes; en el caso concreto de la expresión dominio público, como en tantos otros, la historia nos muestra que es la idea del dominio público la que fue conocida y regulada en Derecho Romano, como romanos son, por separado, los términos dominium y publicum, si bien hay que esperar a la Revolución Francesa para que dicha idea se plasme en la expresión dominio público". 
embargables que, además, están sometidas a una protección especial que se hace efectiva por el sistema de inventarios y catálogos, presunción posesoria, acción administrativa de investigación, facultad de deslinde, recuperación de oficio, potestad sancionadora de la Administración, etc.

Como ocurría en Roma, ahora también son muy distintos (así se desprende de los artículos del Código Civil reproducidos unas líneas más arriba) los criterios clasificatorios. Un principio quizá interesante para este estudio es el que hace alusión a bienes de dominio público natural y bienes de dominio público artificial (clasificación más doctrinal que legal). Ejemplos de los primeros serían las aguas continentales, demanio marítimo, minas, etc. Son las cosas que la autoridad competente declara de dominio público mediante ley estatal, y lo hace para un conjunto completo de ellas en razón de las características naturales que poseen. Los bienes de dominio público artificial se afectan al uso público mediante actos concretos.

Por otro lado, el demanio público se puede clasificar, según su afectación o destino, en bienes demaniales de uso público o general, que están a disposición de todos los ciudadanos para su uso común (caminos, carreteras, plazas, calles, fuentes, puentes), y bienes de servicio público (como mercados, hospitales, museos).

Por lo que respecta a las llamadas por el derecho romano res fiscales o res in patrimonio fisci, estas cosas podrían equipararse a los hoy conocidos como bienes patrimoniales, dada -entre otras causas-su finalidad fiscal. Son, en realidad, bienes que pertenecen al Estado no estando sometidos a ningún régimen especial de protección ni afectados a una utilidad pública.

El derecho positivo español acoge estos bienes en el Código Civil (arts. 340 y 344) y en la Ley del Patrimonio del Estado/Ley de Patrimonio de las Administraciones Públicas (LPAP), en donde a lo largo de su articulado se precisa lo que ha de considerarse patrimonio estatal ${ }^{51} \mathrm{y}$, de modo expreso, se fija la legislación aplicable a los mismos: dicha ley y, subsidiariamente, normas de derecho privado, civil o mercantil.

Los bienes patrimoniales, aun sirviendo de soporte para la realización de funciones públicas, no están afectos a uso o servicio público. Se puede decir que si los bienes demaniales son propiedad pública, los patrimoniales son pro-

51 1. Los bienes no afectados, es decir los que no son de dominio público declarados por medio de la técnica de la afectación, y los no declarados legalmente demaniales. En este apartado, la ley hace la exclusión de entre los patrimoniales, dándoles consideración de demaniales a los edificios propiedad del Estado en los que se alojen órganos del mismo. 2. Los derechos reales y de arrendamiento de que el Estado sea titular, así como aquellos de cualquier naturaleza que deriven del dominio de los bienes patrimoniales.

3. Los derechos de propiedad incorporal que pertenezcan al Estado.

4. Debe añadirse los inmuebles vacantes que estuviesen sin dueño conocido y los de la misma naturaleza detentados o poseídos sin título por entidades particulares, pudiendo reivindicarlos al Estado con arreglo a las leyes. 
piedad privada, pero, como señala Parada Vázquez, ello no implica en absoluto que los bienes patrimoniales de las Administraciones Públicas se puedan equiparar a la propiedad privada de un particular, pues, si bien se aplican normas de derecho privado y su régimen no es tan exorbitante como el del demanio, también su régimen jurídico básico está repleto de especialidades y privilegios.

Deben considerarse bienes patrimoniales - prestando atención a Garrido Falla-:

1. Aquellos bienes que se mantienen en un patrimonio administrativo única y exclusivamente por razón de su rendimiento económico o por la garantía que tal inversión económica supone.

2. Aquellos bienes que las entidades administrativas poseen como instrumentos para el desarrollo de actividades que, no obstante su utilidad pública, están sometidos en bloque a las formas de derecho privado.

3. Aquellos bienes que, a pesar de estar afectos a un servicio público, se regulan por un régimen jurídico positivo esencialmente análogo al de la propiedad civil o que, a falta de reglas expresas, debe entenderse que la titularidad administrativa está suficientemente garantizada con el régimen de la propiedad civil.

$\mathrm{Al}$ igual que los bienes demaniales, también los patromoniales admiten diversas clasificaciones: por su régimen jurídico, disponibilidad, ámbito local, sujeto titular, etc.

Después de este breve recorrido en torno a la concepción actual de bienes demaniales y patrimoniales se puede mantener que estos bienes son, en cierto modo, herederos de aquella clasificación romana que hacía distinción entre res publicae in usu publico (cosas destinadas al uso público) y res in patrimonio fiscil res fiscales/res in pecunia populi ${ }^{52}$ (cosas que satisfacen las necesidades del Estado).

\section{BIBLIOGRAFÍA}

Alburquerque, Juan Miguel. "A propósito del ‘Derecho público romano' del Prof. Dr. Antonio Fernández de Buján", Revista "Iuris tantum", México, Facultad de Derecho de la Universidad Anáhuac, 1997.

Alburquerque, Juan Miguel. La protección o defensa del uso colectivo de las cosas de dominio público: especial referencia a los interdictos de publicis locis (loca, itinera, viae, flumina, ripae), Madrid, 2002.

Arangio-Ruiz, Vincenzo. Istituzioni di diritto romano, Napoli, 1974.

52 Para dicha diferenciación, vid., p. ej., FiLippo Vassalli. "Sul rapporto tra le res publicae e le res fiscales", cit., pp. 3-8. O Pietro Bonfante. Corso di diritto romano, vol. II-1, cit., pp. $82-83$ 
ArChi, Gian Gualberto. "La summa divisio rerum in Gaio e in Giustiniano", en Studia et Documenta Historiae et Iuris, 1937.

Aru, Luigi Y Orestano, Riccardo. Sinopsis de derecho romano, Madrid, 1964.

Biondi, Biondo. "La vendita di cose fuori di commercio", en Studi in onore di Salvatore Riccobono nel XL anno del suo insegnamento, Palermo, 1974.

Bonfante, Pietro. Corso di diritto romano, vol. II, La proprietà, Parte 1, Milano, 1966.

Bove, Lucio. Ricerche sugli agri vectigales, Napoli, 1960.

BranCa Giuseppe. "Le cose extra patrimonium humani iuris", en Annali Triestini, 12, 1941.

Bruns, Carlo Giorgio. Le azioni popolari romane, trad. Scialoja, AG, XXVIII, 1882.

D'Ors, Álvaro. Derecho privado romano, Madrid, 1997.

Di Marzo, Salvatore. Manuale elementare di diritto romano, Torino, 1954.

Di Porto, Andrea. "Interdetti popolari e tutela delle res in usu publico", en Diritto e processo nella esperienza romana, Atti del seminario torinese (4-5 dicembre 1991) in memoria di Giuseppe Provera, Napoli: Jovene, 1994.

EliACHEVITCH, BASILE. La personnalité juridique en droit privé romain, Paris, 1942.

Evans-Jones, Robin y McCormack, GeOfFrey. "The sale of res extra commercium in Roman Law", ZSS, n. ${ }^{\circ} 112,1995$.

Fadda, Carlo. L'azione popolare. Studio di diritto romano ed attuale, t. I, Diritto romano, Torino, 1894

Fernández de Buján, Antonio. Derecho público romano, Madrid, 7. a ed., 2004.

Franchini, Flaminio. "Strade pubbliche, private e vicinali", NDI, t. XII, 1940.

Fuenteseca, Pablo. Derecho privado romano, Madrid, 1978.

Gaudemet, Jean. "Utilitas publica", Revue Historique de Droit Français et Étranger, 1985.

Grosso, Giuseppe. Corso de diritto romano, Le cose, Torino, 1941.

Guarino, Antonio. Diritto privato romano, Napoli, 1970.

IgLESIAS, JuAn. Derecho romano. Historia e instituciones, Barcelona, 1993.

IgLESIAS, Juan. Derecho romano. Instituciones de derecho privado, Barcelona, 1979. 
IHERING Rudolf von. Der Zweck im Recht, I, Leipzig, 1884.

Impallomeni, Giambattista. "In tema di strade vicinali", en Scritti di diritto romano e tradizione romanistica, Padova, 1996.

Kaser, Max. Römisches Privatrecht, München, 1981.

Maddalena, PaOlo. Gli incrementifluviali nella visione giurisprudenziale classica, Napoli, 1970.

Melillo, Generoso. "Interdicta e operis novi nuntiatio iuris publici tuendi gratia", Labeo, n. ${ }^{\circ} 12,1966$.

MurGa, José Luis. "La popularidad de las acciones en las leyes municipales de la Bética", RIDA, 1991.

MurGA, José LuIs. "Las acciones populares en el municipio de Irni", BIDR, LXXXVIII, 1985.

Murga, José Luis. "Las acciones populares en la lex Coloniae Genetivae Juliae", en Seminarios complutenses, I, 1990.

Orestano, Riccardo. Il problema delle persone giuridiche in diritto romano, Torino, 1968.

Ortega Carrillo de Albornoz, Antonio. Derecho privado romano, Málaga, 2002.

Palma, Antonio. "Le strade romane nelle dottrine giuridiche e gromatiche dell'età del principato", ANRW II, Berlin-New York: Walter de Gruyter, 1982.

Palma, Antonio. Iura vicinitatis. Solidarietà e limitazioni nel rapporto di vicinato in diritto romano dell'età classica, Torino, 1988.

Pugliese, Giovanni. Istituzioni di diritto romano, Padova, 1986.

Sanfilippo, Cesare. Istituzioni di diritto romano, Catania, 1964

Sargenti, Manlio. "Le 'res' nel diritto del Tardo Impero", Labeo, n. . 40, 1994-1.

Scherillo, Gaetano. Lezioni di diritto romano, Le cose, Milano, t. I, 1945.

Scialoja, VitTorio. Prefazione alla traduzione de Le azioni popolari romane, de Bruns, $A G$, XXVIII, 1882.

Segrè, Gino. Corso di diritto romano. Le cose, la proprietà, gli altri diritti reali ed il possesso I, Torino, 1927.

Serrigny Denis. Droit public et administratif romain, Paris, 1862, t. I. 
Vassalli, Filippo. "Sul rapporto tra le res publicae e le res fiscales", en Studi Senesi, vol. 25, 1908 (= Studi giuridici, vol. II, Milano, 1960.

Volterra, Edoardo. Istituzioni di diritto privato romano, Roma, 1972. 